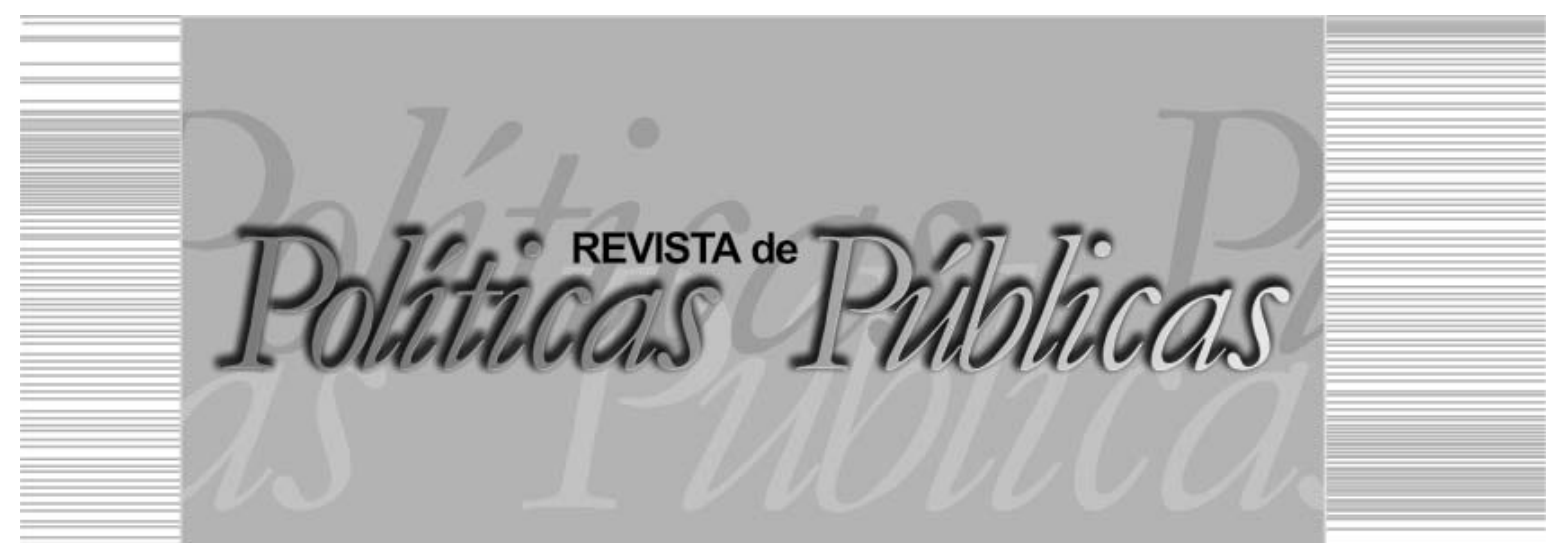

\title{
OS SERVIDORES PÚBLICOS ESTÃO ADERINDO A FUNPRESP? UM ESTUDO EM UMA INSTITUIÇÃO FEDERAL DE ENSINO
}

Tatiane Sartori ${ }^{l}$

Universidade Federal de Santa Maria (UFSM)

Luana dos Santos Fraga ${ }^{2}$

Universidade Federal de Santa Maria (UFSM)

Kelmara Mendes Vieira ${ }^{3}$

Universidade Federal de Santa Maria (UFSM)

Daniel Arruda Coronel ${ }^{4}$

Universidade Federal de Santa Maria (UFSM)

\section{Resumo}

Este artigo tem por objetivos: identificar o percentual de adesões dos servidores em um dos Campi de uma Universidade Federal; descrever o perfil dos respondentes, segundo os que aderiram e não aderiram ao fundo de previdência complementar; avaliar os motivos da adesão e não adesão à FUNPRESP; verificar o nível de conhecimento, riscos e retornos acerca da FUNPRESP, segundo os

\footnotetext{
Secretariado Executivo Bilingue/UNISINOS. Doutora em Administração. Secretária Executiva na Universidade Federal de Santa Maria (UFSM). E-mail: tatianesartori@, yahoo.com.br

2 Economista. Mestre em Administração. Bolsista no Programa de Pós-Graduação em Administração da Universidade Federal de Santa Maria (UFSM). E-mail: luana.fraga92@ gmail.com

3 Administradora. Doutora em Administração. Professora Associada da Universidade Federal de Santa Maria (UFSM). E-mail: kelmara@terra.com.br

4 Economista/Administradora. Doutor em Economia Aplicada. Professor Adjunto da Universidade Federal de Santa Maria (UFSM). E-mail: daniel.coronel@uol.com | Universidade Federal de Santa Maria - UFSM $\mid$ Av. Roraima, 1000. Bairro Camobi. Santa Maria - RS | CEP: 97105-900
} 
que aderiram e não aderiram e; analisar o nível de informações sobre contratos, relatórios e ajustes dos que aderiram. A pesquisa constitui-se em um estudo exploratório, abordagem quantitativa e aplicação de questionários. A maioria dos servidores não aderiu à FUNPRESP e estes desconhecem os riscos e retornos que o fundo proporciona. Conclui que, em contrapartida, os que aderiram acreditam que o fundo dê um retorno financeiro positivo e discordam receber informações importantes como os ajustes da parcela e relatórios atualizados Palavras-chave: Plano de Previdência Complementar, FUNPRESP, servidores públicos.

\title{
PUBLIC WORKERS ARE ENTERING THE FUNPRESP? A STUDY IN AN INSTITUTION OF FEDERAL EDUCATION
}

\begin{abstract}
This article aims to: identify the percentage of server accessions in one of the Campuses of a Federal University; Describe the profile of the respondents according to those who joined and did not join the supplementary pension fund; evaluate the reasons for joining and not joining FUNPRESP; verify the level of knowledge, risks and returns about FUNPRESP, according to those who have adhered and have not joined; analyze the level of information on contracts, reports and adjustments of those who joined. The research consisted of an exploratory study, quantitative approach and application of questionnaires. Most of the servers did not join FUNPRESP and they are unaware of the risks and returns that the fund provides. On the other hand, those who joined believe that the fund will make a positive financial return and disagree with receiving important information such as portion adjustments and up-to-date reports. Key words: Supplementary Pension Plan, FUNPRESP, public workers.
\end{abstract}

\section{INTRODUÇÃO}

O Regime Previdenciário no Brasil iniciou seu ciclo a partir da Constituição de 1988, a qual representou um marco na história democrática brasileira. A Constituição marcou a reformulação do sistema fiscal fazendo com que houvesse uma maior eficiência do sistema tributário. Porém, até o ano de 1998, praticamente não existia um sistema de previdência no serviço público da União, dos Estados e dos Municípios. (PACHECO FILHO; WINKLER, 2005). Ao contrário do setor privado, onde a aposentadoria é limitada pelo teto do Instituto Nacional do Seguro Social (INSS), a aposentadoria no setor público sempre foi obtida com os vencimentos integrais, porém a regra de aposentadoria mudou a partir de fevereiro de 2013 quando entrou em vigor a Lei $\mathrm{n}^{\mathrm{o}} 12.618$, de 30 de abril de 2012, que 
instituiu o novo regime de previdência complementar para o funcionalismo federal. A gestão da nova previdência é de responsabilidade do Fundo de Previdência Complementar do Servidor Público Federal (FUNPRESP) e cada um dos poderes da União tem o seu próprio fundo. (AMARAL; GIANBIAGI; CAETANO, 2013; FUNDAÇÃO DA PREVIDÊNCIA COMPLEMENTAR O SERVIDOR PÚBLICO FEDERAL, 2016). Segundo a nova regra, o Regime Próprio de Previdência Social (RPPS) proporcionará o benefício previdenciário até o valor do teto do INSS, que atualmente é de R \$ 5.189,82 (INSTITUTO NACIONAL DO SEGURO SOCIAL, 2016) e a FUNPRESP proporcionará o benefício previdenciário complementar para aqueles que optarem por participar dos seus planos.

No período de fevereiro de 2013 a agosto de 2014 a taxa de adesão a FUNPRESP foi de 72\%. No período de janeiro a agosto de 2014, a taxa de adesão para servidores acima do teto atingiu 25\% contra 15\%; em 2013, porém, o número de adesões das universidades federais ficou abaixo do esperado (FUNDAÇÃO DA PREVIDÊNCIA COMPLEMENTAR O SERVIDOR PÚBLICO FEDERAL, 2016). Para Pena (2014), as adesões dos servidores nessa área representa um dos maiores desafios à estratégia de ampliação da FUNPRESP devido às características de descentralização e interiorização das Universidades e Institutos Federais, e também pelas diversas manifestações contrárias das entidades representativas de classe que trabalham a favor da não adesão ao plano.

Considerando que o servidor público federal pretende ter uma aposentadoria economicamente estável ao se aposentar, e que o mesmo precisa planejá-la a longo prazo para que possa usufruir dos rendimentos na aposentadoria, este artigo tem como objetivos: I) identificar o percentual de adesões dos servidores em um dos Campi de uma Universidade Federal; II) descrever o perfil dos respondentes segundo os que aderiram e não aderiram ao fundo de previdência complementar; III) avaliar os motivos da adesão e não adesão à FUNPRESP; IV) verificar o nível de conhecimento, riscos e retornos acerca da FUNPRESP, segundo os que aderiram e não aderiram e, V) analisar o nível de informações sobre contratos, relatórios e ajustes dos que aderiram.

Este trabalho inova em diferentes aspectos. Primeiro, por se tratar de um tema recente onde o número de estudos ainda é muito reduzido. Segundo, a análise do impacto desta legislação na carreira 
dos servidores públicos se faz necessária para que haja novas políticas públicas referentes ao tema. Terceiro, por ser inédito no âmbito de uma Universidade Federal.

O estudo está dividido em cinco itens. O primeiro trata do Sistema Previdenciário Brasileiro, onde haverá o embasamento teórico quanto ao tema. O segundo item expõe sobre o Plano de Previdência Complementar e o FUNPRESP. O terceiro descreve a metodologia, e os itens quarto e quinto demonstram os resultados e as considerações finais do estudo.

\section{O SISTEMA PREVIDENCIÁRIO BRASILEIRO}

O sistema previdenciário é definido por Campos (2011, p. 68) como sendo o "[...] conjunto de normas, regras e princípios harmônicos que informam e regem a disciplina previdenciária de determinado grupo de seres humanos, pelo universo de segurados e dependentes que cobrem." Este conjunto de normas e regras é diferenciado em cada país, sendo que no Brasil existem três regimes previdenciários onde dois deles são compulsórios, isto é, obrigatórios, e um deles é facultativo, e a participação pessoal depende exclusivamente do interesse do indivíduo em contribuir para um plano privado de aposentadoria.

A composição do sistema previdenciário no Brasil é alicerçada por dois sistemas, um gerido pelo poder público, de filiação obrigatória para todos os trabalhadores e fundado em um sistema de repartição, de fundo único; outro administrado pela iniciativa privada, de filiação facultativa, fundado em um sistema de capitalização, onde cada segurado contribui para um fundo próprio (VAZ, 2009). O atual sistema previdenciário brasileiro pode ser analisado através da Figura 1. O Regime Geral de Previdência Social (RGPS), do INSS, é responsável pela substituição da renda do trabalhador contribuinte quando ele perde a capacidade de trabalho por doença, invalidez, idade avançada, morte ou desemprego involuntário, ou por maternidade ou reclusão. Pode ser opcional ou privado (Figura 1), havendo a adesão obrigatória, quando há o exercício de atividade remunerada, ou facultativa (autônomo), quando há a intenção de contribuir mesmo não tendo vínculo empregatício. (PACHECO FILHO, WINCKLER, 2005; GOES, 2011). 
OS SERVIDORES PÚBLICOS ESTÃO ADERINDO A FUNPRESP? UM ESTUDO EM UMA INSTITUIÇÃO FEDERAL DE ENSINO

Figura 1 - Descrição dos regimes de previdência do Sistema Previdenciário Brasileiro

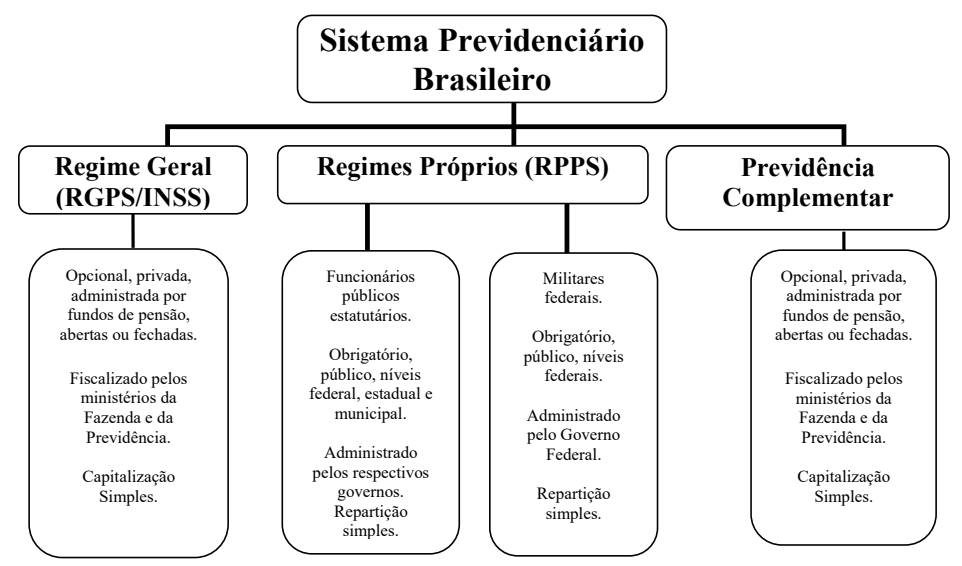

Fonte: Adaptado de: BRASIL. Portaria n. 154, de 15 de maio de 2008. Disciplina procedimentos sobre a emissão de certidão de tempo de contribuição pelos regimes próprios de previdência social. Diário Oficial da União, Brasília, DF, 2008.

O RPPS destina-se exclusivamente aos funcionários públicos (federais, estaduais, municipais e do Distrito Federal) que contam com um sistema próprio de contribuição tendo assim um cálculo diferenciado de benefícios (REZENDE, 2001). A FUNPRESP foi instituída no ano de 2013, através da Lei $\mathrm{n}^{\circ} 12.618 / 2012$ e prevê a instituição do regime de previdência complementar aos servidores públicos de cargo efetivo (MONTESINOS, 2007). O servidor que ingressou no serviço público antes de a Lei ${ }^{\circ}$ 12.618/2012 ser sancionada, terá o cálculo da aposentadoria realizado através da média aritmética das maiores remunerações, podendo haver uma redução no montante do valor a ser recebido na aposentadoria em relação ao salário da ativa. Para os que ingressaram no serviço público após o período citado, passarão a contribuir em cima do valor do teto do RGPS e poderão optar por participar de um regime complementar, seja o do servidor público (MONTESINOS, 2007; MARINHO; AFONSO, 2014; FUNDAĈ̃̃O DA PREVIDÊNCIA COMPLEMENTAR O SERVIDOR PÚBLICO FEDERAL, 2016).

De acordo com Marinho e Afonso (2014), existem atualmente quatro situações de aposentadoria para os servidores da União baseadas na Emenda Constitucional (EC) $\mathrm{n}^{\circ} 41$, de 19 de dezembro de 2003 e na Lei ${ }^{\circ} 12.618 / 2012$ que são os ingressantes antes da EC $n^{\circ}$ 
41/2003: podem se aposentar com direito à paridade e integralidade salarial, desde que respeitados os critérios de concessão para aposentadoria - 60 anos de idade e 35 de contribuição (homens) ou 55 anos de idade e 30 de contribuição (mulheres); os ingressantes após a $E C n^{\circ} 41 / 2003$ e não optantes pelo regime de previdência complementar - o valor do benefício é calculado com base na regra do RGPS; os ingressantes após a $\mathrm{EC} \mathrm{n}^{\circ} 41 / 2003$ e optantes pelo regime de previdência complementar - o valor do benefício é calculado com base na regra do RGPS e; os ingressantes após a aprovação da Lei ${ }^{\circ}$ $12.618 / 2012$ - o valor do benefício é calculado com base na regra do RGPS. O teto do benefício é o limite do RGPS, podendo o servidor complementar a sua aposentadoria através de contribuição para o Fundo de Previdência Complementar.

\section{A PREVIDÊNCIA COMPLEMENTAR: estudos empíricos}

A previdência complementar surgiu no Brasil, de forma regulamentar, com a Lei $\mathrm{n}^{\circ} .6 .435$, de 15 de julho de 1977 , em consonância com a experiência norte-americana do ERISA (Employee Retirement IncomeSecurity Act), na necessidade de regulamentação da canalização da poupança previdenciária ao desenvolvimento do mercado de capitais no país a partir do programa nacional de desenvolvimento e do funcionamento de algumas entidades de previdência privada ligadas ao setor estatal. (PENA, 2012). Os estudos empíricos sobre o tema iniciaram na década de 20, a partir do surgimento do plano de previdência complementar no Brasil (SANTOS, 2009) dando destaque para a matemática atuarial, a política e a educação financeira.

Em relação à matemática atuarial, destacam-se os trabalhos de Barro (1978), Winklevoss (1993), Bowers (1997) e Davis (2000) os quais fornecem uma boa introdução teórica aos conceitos da matemática atuarial, porém trabalham o fundo de previdência de uma forma ampla, diferentemente de Ferreira (2008), que analisou as condições atuariais para a criação do FUNPRESP e como seria o novo sistema previdenciário após o funcionamento desse fundo, trabalhando assim resultados específicos. De acordo com o autor, o novo sistema previdenciário pagará benefícios menores para os servidores que ingressarem depois da criação do fundo quando comparados com os atuais servidores. Nesse caso o autor refere-se a todos os servidores, não especificando público alvo do estudo. Em 
contrapartida, Amaral, Gianbiagi e Caetano (2013) trabalharam especificamente os servidores da União a partir da elaboração de um modelo de simulação estocástico para as variáveis financeiras e atuariais onde foram comparados os valores médios e a distribuição dos benefícios previdenciários oferecidos antes e depois da entrada em vigor da FUNPRESP. O estudo empregou conceitos e técnicas de matemática atuarial para o cálculo dos fluxos de receitas e despesas futuras nas condições anterior e posterior à Lei ${ }^{\circ} 12.618 / 2012$ que criou a FUNPRESP e concluiu que a nova previdência pode oferecer tanto um retorno de benefícios superior quanto inferior, mas o risco recairá sobre o servidor. $\mathrm{O}$ setor de previdência complementar foi discutido também em Coimbra e Toyoshima (2009), quando analisaram a previdência complementar observando os níveis de concentração, os efeitos das políticas de fiscalização, o grau de eficiência das empresas e as barreiras à entrada e à saída de firmas no setor. A metodologia básica consistiu no cálculo do Índice de Gini e no Método de Análise Envoltória de Dados. Cardoso e outros (2006) realizaram um estudo exploratório que teve como objetivo quantificar o carregamento de contingência sobre as provisões matemáticas de previdência complementar para entidades de diferentes portes, demonstrando a probabilidade para diferentes arranjos previdenciários. Montesinos (2007) fez um estudo focado na comparação de um plano fechado de previdência complementar de uma instituição privada, com dois planos oferecidos por um banco privado nacional, Plano Gerador de Benefício Livre (PGBL) e Vida Geradora de Benefício Livre (VGBL) com a finalidade de identificar qual a modalidade de previdência privada, aberta ou fechada, com melhor desempenho para suprir as deficiências da Previdência Social.

$\mathrm{O}$ estudo que trabalhou alguns aspectos voltados à previdência dos servidores públicos foi realizada por Silveira e outros (2011) que analisou alguns aspectos do diálogo da proposta de introdução de um sistema de previdência complementar no qual analisou o modelo atual de previdência, apresentando a evolução da quantidade e do valor dos benefícios pagos aos servidores inativos ao longo do tempo; o custo de seu financiamento; e o impacto regressivo dos benefícios de previdência dos servidores na distribuição de renda do país. Apresentou ainda o Projeto de Lei ${ }^{\circ} 1.992$, de setembro de 2007, que trata da criação da previdência complementar, e, por fim, uma simulação dos custos implicados na transição entre os modelos atual e o futuro. Em se tratando do plano de previdência comple- 
mentar e a educação financeira, um estudo realizado por Pinheiro (2008), através de um estudo descritivo, o qual discutiu a relevância da educação financeira para o segmento da previdência complementar, mais especificamente, discutiu a promoção de práticas educativas como instrumento para melhorar o funcionamento dos fundos de pensão, mudar hábitos culturais que podem prejudicar a qualidade de vida do brasileiro, como baixos níveis de poupança previdenciária, enfrentar as consequências advindas da transição demográfica e do risco de longevidade, permitir que o indivíduo realize escolhas financeiras adequadas ao seu perfil e auxiliar as atividades do órgão governamental de fiscalização dos fundos de pensão.

\subsection{Fundação de Previdência Complementar do Servidor Público Federal (FUNPRESP)}

A FUNPRESP foi criada através do Decreto $\mathrm{n}^{\circ} 7.808$, de 20 de setembro de 2012 com a finalidade de administrar e executar planos de benefícios, de caráter previdenciário complementar, para os servidores públicos titulares de cargo efetivo da União. Seu objetivo é proporcionar a possibilidade de contratação de uma renda adicional. Com essa contratação, o servidor e a União irão contribuir para a formação de reservas financeiras que irão possibilitar o pagamento futuro de renda (FUNDAĈ̃O DA PREVIDÊNCIA COMPLEMENTAR O SERVIDOR PÚBLICO FEDERAL, 2016). O plano de benefícios da FUNPRESP é o de contribuição no qual são formadas poupanças individuais por meio de contribuições definidas previamente, depositadas pelo ente público ou empresa (patrocinador) e pelo participante. $\mathrm{O}$ valor que o participante irá receber no momento da aposentadoria dependerá diretamente do quanto foi acumulado em conta individual, do período em que os depósitos foram efetuados e da rentabilidade obtida nas aplicações financeiras (CHAGAS et al., 2015; FUNPRESP, 2016). Pela Orientação Normativa $n^{0} 12$, de 25 setembro de 2013, da Secretária de Gestão Pública do Ministério do Planejamento, Orçamento e Gestão, todas as unidades de Recursos Humanos do Poder Executivo Federal devem, obrigatoriamente, oferecer o plano de benefícios aos novos servidores públicos federais que ingressaram por concurso público a partir da data de 04 de fevereiro de 2013 (PENA, 2014).

No ano de 2015, a FUNPRESP apresentou os dados do relatório anual onde apresentou que o estado do Rio Grande do Sul teve 


\section{OS SERVIDORES PÚBLICOS ESTÃO ADERINDO A FUNPRESP? UM ESTUDO EM UMA INSTITUIÇÃO FEDERAL DE ENSINO}

14,7\% de adesões no período de fevereiro de 2013 a agosto de 2014. Contabilizou-se também o tempo médio de ingresso ao plano após entrada do servidor no serviço público, sendo que em fevereiro de 2013 era de 210 dias e em agosto de 2014 de 11 dias (FUNPRESP, 2016). O Relatório anual da FUNPRESP $(2015,2016)$ registrou também o perfil das não adesões, sendo os servidores por gênero do sexo masculino $(53 \%)$ e feminino $(47 \%)$ com faixa etária entre 25 a 34 anos $(59,5 \%)$ e 35 a 44 anos $(28,5 \%)$ totalizando $88 \%$ do total de não adesões. Outro dado importante é o perfil de não adesões por órgãos, sendo que dentre os 18 citados (30\%), 14 são universidades. Diante do exposto, o presente trabalho corrobora com a proposta de estudar o perfil dos servidores de uma universidade federal quanto á adesão e não adesão à FUNPRESP.

\section{MÉTODO}

O estudo considerou como universo de pesquisa os servidores públicos federais da Universidade Federal de Santa Maria, lotados no Campi de Cachoeira do Sul, o qual iniciou suas atividades no ano de 2014. Devido a este Campi ser novo, ainda há um número reduzido de servidores lotados, sendo que no total são cinquenta e seis servidores divididos entre professores e técnico- administrativos em educação. Diante disso, salienta-se que a amostra contou com o número geral de servidores, sendo que no total obteve-se trinta e seis respondentes. A escolha do universo e amostra justifica-se pelo fato dos servidores lotados no Campi Cachoeira do Sul serem recentes na universidade, atingindo assim o público alvo do estudo, que são servidores ingressantes depois da lei que implantou a FUNPRESP com fundo de previdência complementar no setor público.

A pesquisa constitui-se em um estudo exploratório, com abordagem quantitativa. A aplicação do instrumento de coleta de dados (questionário) foi realizada no mês de agosto de 2015. O questionário foi formado por seis blocos de perguntas. $\mathrm{O}$ primeiro refere-se ao percentual de adesão e ao conhecimento da existência da FUNPRESP. O segundo trata de questões sobre o perfil dos respondentes, onde aborda a idade, gênero, estado civil, dependentes, nível de escolaridade, cargo e renda bruta mensal. O terceiro bloco compreende as razões pela adesão e não adesão do servidor. O quarto bloco trata do conhecimento da Lei ${ }^{\circ} 12.618 / 2012$, adesão ao fundo e alíquotas. O quinto bloco refere-se ao conhecimento voltado à FUN- 
PRESP, seus regulamentos, relatórios, formas de pagamento, tempo de contribuição e condições de saída. O sexto bloco trata do risco e retorno, visando aplicações, aposentadoria, operações financeiras e retorno financeiro. Por fim, o sétimo bloco trata das informações adquiridas pelo servidor que aderiu à FUNPRESP, bem como informações de contratos, relatórios, ajustes e reajustes. Salienta-se que o sétimo bloco foi o único respondido somente pelos servidores que aderiram.

Todas as questões foram desenvolvidas pelos pesquisadores devido à não existência de trabalhos nessa temática que pudessem fornecer escalas já validadas. Assim, realizou-se um pré-teste com cinco servidores, além de ter passado por três especialistas. Optou-se pela utilização da escala do tipo likert nos blocos quatro, cinco e seis, sendo questões de quatro pontos com alternativa de resposta: não sei (1), discordo (2), indiferente (3), e concordo (4). Tal escala foi escolhida por ser amplamente utilizada na literatura e por ser a que melhor se adequou ao escopo da pesquisa.

Para a análise dos dados coletados foram utilizadas estatísticas descritivas, para as quais foi utilizado o software SPSS 20.0®. Para a realização das análises, foi criada uma variável binária com valor zero (0) para os servidores que não aderiram à FUNPRESP e valor um (1) para servidores que aderiram à FUNPRESP. Além disso, foram calculadas as médias de cada conjuntos de questões, a fim de verificar o nível de conhecimento geral sobre a FUNPRESP, sobre o risco e retorno financeiros do Fundo e, do nível de informações dos respondentes. A média varia entre zero e quatro, onde zero representa baixo nível de conhecimento e quatro alto nível de conhecimento.

\section{ANÁLISE E DISCUSSÃO DOS RESULTADOS}

De forma a atender os objetivos, inicialmente apresenta-se o percentual de adesão dos servidores ao plano de previdência complementar. Verificou-se ainda, o percentual de respondentes que conhecem a FUNPRESP, se esse conhecimento é superficial ou mais aprofundando, com o conhecimento das regras, e se já foi procurado por algum representante da Fundação (Tabela 1). 
OS SERVIDORES PÚBLICOS ESTÃO ADERINDO A FUNPRESP? UM ESTUDO EM UMA INSTITUIÇÃO FEDERAL DE ENSINO

Tabela 1 - Adesão e conhecimento acerca da existência da FUNPRESP

\begin{tabular}{c|c|c}
\hline Variável & Valores & $\%$ \\
\hline \multirow{2}{*}{ Você aderiu à FUNPRESP? } & Sim & 38,90 \\
\cline { 2 - 3 } & Não & 61,10 \\
\hline \multirow{2}{*}{ Você conhece a FUNPRESP? } & Sim, conheço as regras. & 25,00 \\
\cline { 2 - 3 } $\begin{array}{c}\text { Algum representante da FUNPRESP } \\
\text { Ihe procurou para explicar o plano de } \\
\text { previdência? }\end{array}$ & Não & 69,44 \\
\cline { 2 - 3 } \begin{tabular}{c} 
pim superficialmente. \\
\cline { 2 - 3 }
\end{tabular} & Sim & 5,56 \\
\hline
\end{tabular}

Fonte: Elaborada pelos autores.

Observa-se que a maioria dos servidores $(61,10 \%)$ que ingressaram na instituição a partir de 2013, não aderiram ao fundo de previdência complementar oferecido pelo governo. Quando questionados se conheciam a FUNPRESP, apenas 5,56\% afirmaram que não conheciam, e 94,5\% destacaram que conheciam superficialmente ou mais detalhadamente, com o conhecimento das regras (25\%). Quanto a serem procurados por algum representante da FUNPRESP, para que assim obtivessem maiores informações acerca do plano de previdência complementar, $78 \%$ dos servidores declararam ter sido procurados. A maioria dos servidores, mesmo não aderindo, tinham algum conhecimento do plano e obtiveram maiores explicações em função de que foram procurados por representantes da Fundação. Logo, admite-se que a não adesão não está vinculada à falta de conhecimento da existência da FUNPRESP. Posteriormente, analisou-se o perfil dos respondentes segundo os que aderiam e não aderiram ao plano de previdência complementar, de acordo com as variáveis gênero, idade, estado civil, dependentes, escolaridade, renda e cargo (Tabela 2).

Tabela 2 - Análise descritiva do perfil dos respondentes segundo os que aderiram e não aderiram à FUNPRESP

\begin{tabular}{c|c|c|c}
\hline \multirow{2}{*}{ Variável } & Valores & $\begin{array}{c}\text { Aderiu } \\
\text { FUNPRESP }(\%)\end{array}$ & Não aderiu FUNPRESP (\%) \\
\hline \multirow{2}{*}{ Gênero } & Homem & 50,00 & 50,00 \\
\cline { 2 - 4 } & Mulher & 50,00 & 50,00 \\
\hline
\end{tabular}


Tatiane Sartori $\mid$ Luana dos S. Fraga $\mid$ Kelmara M. Vieira $\mid$ Daniel A. Coronel

\begin{tabular}{|c|c|c|c|}
\hline \multirow{4}{*}{ Idade } & Até 27anos & 21,43 & 27,27 \\
\hline & De 28 a 30 anos & 21,43 & 36,36 \\
\hline & De 31 a 33 anos & 28,57 & 22,73 \\
\hline & Acima de 33 anos & 28,57 & 13,64 \\
\hline \multirow{2}{*}{ Estado Civil } & Casado(a) & 21,43 & 18,18 \\
\hline & Solteiro(a) & 78,57 & 81,82 \\
\hline \multirow{2}{*}{$\begin{array}{c}\text { Possui } \\
\text { dependentes }\end{array}$} & Não & 85,71 & 90,91 \\
\hline & Sim & 14,29 & 9,09 \\
\hline \multirow{6}{*}{ Escolaridade } & Ensino Médio & 0,00 & 9,09 \\
\hline & Ensino Superior & 0,00 & 40,91 \\
\hline & Pós-Graduação & 0,00 & 13,64 \\
\hline & Especialização & 0,00 & 4,55 \\
\hline & Mestrado & 42,86 & 22,73 \\
\hline & Doutorado & 57,14 & 9,09 \\
\hline \multirow{3}{*}{ Renda } & De $R \$ 2.000,01$ a $R \$ 3.000,00$ & 0,00 & 22,73 \\
\hline & De $R \$ 3.000,01$ a $R \$ 4.000,00$ & 0,00 & 22,73 \\
\hline & De $R \$ 4.000,01$ a $R \$ 5.000,00$ & 0,00 & 13,64 \\
\hline Variável & Valores & $\begin{array}{c}\text { Aderiu } \\
\text { FUNPRESP (\%) }\end{array}$ & Não aderiu FUNPRESP (\%) \\
\hline \multirow{3}{*}{ Renda } & De $R \$ 5.000,01$ a $R \$ 7.000,00$ & 50,00 & 22,73 \\
\hline & De $R \$ 7.000,01$ a $R \$ 10.000,00$ & 42,86 & 13,64 \\
\hline & Mais de $\mathrm{R} \$ 10.000,00$ & 7,14 & 4,55 \\
\hline \multirow{2}{*}{ Cargo } & Técnico Administrativo & 0,00 & 72,7 \\
\hline & Professor do Magistério Superior & 100,0 & 27,30 \\
\hline \multirow{2}{*}{$\begin{array}{l}\text { É o } 1^{\circ} \\
\text { Emprego } \\
\text { Público? }\end{array}$} & Não & 21,40 & 50,00 \\
\hline & Sim & 78,60 & 50,00 \\
\hline
\end{tabular}

Fonte: Elaborada pelos autores.

Dentre os respondentes que aderiram ao fundo de previdência complementar, $50 \%$ são homens e $50 \%$ são mulheres, sendo a maioria $(57,14 \%)$ com idade entre 31 anos ou mais. São solteiros $(78,57 \%)$, sem dependentes $(85,71 \%)$, com formação de mestres $(42,86 \%)$ e doutores $(57,14 \%)$. A renda mensal dos que aderiram está entre $\mathrm{R} \$ 5.000,00$ a $\mathrm{R} \$ 10.000,00$ e dos servidores que aderiram, 78,6\% estão no primeiro emprego público. 


\section{OS SERVIDORES PÚBLICOS ESTÃO ADERINDO A FUNPRESP? UM ESTUDO EM UMA INSTITUIÇÃO FEDERAL DE ENSINO}

Em relação aos servidores que não aderiram, a metade são mulheres, sendo a maioria dos entrevistados com idade média entre 28 e 33 anos $(59,09 \%)$, solteiros $(81,82 \%)$ e sem dependentes $(90,91 \%)$. Quanto à escolaridade, 40,91\% possuem ensino superior, seguido de $22,73 \%$ com mestrado e, $9,09 \%$ com doutorado. A maioria dos entrevistados que não aderiu são Técnicos Administrativos em Educação (72,7\%) e possuem a faixa salarial entre $\mathrm{R} \$ 2.000,00$ e R\$ 5.000,00 (59,10\%). Os servidores que não aderiram à FUNPRESP são em maioria técnicos administrativos com ensino superior e uma menor faixa salarial. Atualmente o salário de um técnico-administrativo em educação, com curso superior, é de R $\$ 2.432,00$ (BRASIL, [2016]). Dessa forma, o salário pode ser um dos motivos pela não adesão, pois o técnico administrativo teria que aplicar mensalmente no fundo uma quantia de $\mathrm{R} \$ 206,72$ mensais (para a alíquota de $8,5 \%$ ), o que pode representar um alto valor diante do salário recebido. Já os que aderiram são professores universitários, com faixa salarial maior, podendo investir no fundo de previdência sem que isso altere significativamente sua renda mensal. A Tabela 3 trata dos servidores que aderiram à FUNPRESP, tipos de informação que buscaram antes de aderir e, o motivo da adesão.

Tabela 3 - Questionamentos aos servidores que aderiram à FUNPRESP

\begin{tabular}{l|r}
\hline Você aderiu à FUNPRESP? & Total em \% \\
\hline Sim & 38,89 \\
Que tipo de informação buscou antes de aderir? & \\
Plano de Benefícios & 37,50 \\
Tipo de resgate & 31,25 \\
Valor a contribuir & 18,75 \\
Restituições financeiras e descontos & 12,50 \\
& \\
Qual o motivo pela adesão? & \\
Acho mais vantajoso do que um plano de previdência privado & 42,86 \\
Foi a única opção quando entrei na Universidade & 28,57 \\
Não busquei outras informações & 21,43 \\
Meus colegas aderiram & 7,14 \\
\hline
\end{tabular}

Fonte: Elaborada pelos autores.

Observa-se na Tabela 3 que menos da metade dos servidores aderiram à FUNPRESP, totalizando 38,89\%. Dentre os aderentes, $37,5 \%$ buscaram informações do plano de benefícios e do tipo de 
resgate que é oferecido $(31,25 \%)$. Os principais motivos para adesão foram o fato de acharem mais vantajoso aderir ao plano de previdência complementar do que a um plano de previdência privado $(42,86 \%)$ e por ter sido a única opção quando entraram na Universidade $(28,57 \%)$. Apenas 7,14\% declararam ter aderido à FUNPRESP em função dos colegas aderirem. Grande parte dos servidores se pautam principalmente em informações do plano de benefícios e tipo de resgate antes de aderirem. Contudo, cerca de $21 \%$ deles não buscaram informações, aderiram pelo simples fato de se preocuparem com os rendimentos após a aposentadoria e essa ter sido a única opção, a qual obtiveram informações quando ingressaram na universidade. Demonstra-se, assim, a importância da divulgação da FUNPRESP, dessa procura dos representantes da fundação aos servidores ingressantes, para que eles possam ter conhecimento e decidirem com base em informações claras e fidedignas. Na Tabela 4 são apresentadas as questões respondidas pelos servidores que não aderiram.

Tabela 4 - Questionamentos aos servidores que não aderiram à FUNPRESP

\begin{tabular}{l|r}
\hline Você aderiu à FUNPRESP? & Total em \% \\
\hline Não & 61,11 \\
Qual o motivo pela não adesão? & \\
Acredita em outros investimentos & 36,36 \\
Não pensou na aposentadoria & 27,27 \\
É da carreira antiga & 9,09 \\
O salário não atinge o teto & 9,09 \\
Não tem renda disponivel para pagar plano de previdência & 4,55 \\
Acredita não ser vantajoso hoje & 4,55 \\
Por ser uma nova proposta de aposentadoria, não confia no plano & 4,55 \\
Não tem informações suficientes sobre a FUNPRESP & 4,55 \\
& \\
A sua opção em não aderir é definitiva? & \\
Penso em aderir no futuro & 50,00 \\
Está convicto que não quer aderir & 36,36 \\
Não busquei outras informações & 21,43 \\
Sem resposta & 13,64 \\
\hline
\end{tabular}

Fonte: Elaborada pelos autores

Visualiza-se que, dentre os respondentes, $61,11 \%$ dos servidores não aderiram à FUNPRESP. Os principais motivos foram por acreditar em outros investimentos melhores do que o fundo de 


\section{OS SERVIDORES PÚBLICOS ESTÃO ADERINDO A FUNPRESP? UM ESTUDO EM UMA INSTITUICYÃO FEDERAL DE ENSINO}

previdência $(36,36 \%)$ e por ainda não terem pensado em sua aposentadoria a ponto de adquirir o plano de previdência complementar $(27,27 \%)$. Os motivos de não ter renda disponível para pagar plano de previdência; acreditar não ser vantajoso hoje; não confiar no plano e não ter informações suficientes obtiveram pequenos percentuais $(4,55 \%)$. Mais de um quarto dos indivíduos que não aderiram ainda não perceberam que no momento da aposentadoria, se não existir uma complementação da renda, seja por reservas financeiras realizadas ao longo da vida, por investimentos ou adesão de um fundo de previdência complementar, suas rendas poderão sofrer reduções, caso o salário seja superior ao teto do INSS. Posteriormente, a fim de identificar o conhecimento dos entrevistados sobre a FUNPRESP, foram apresentadas questões acerca da Lei $n^{\circ} 12.618 / 2012$, adesão ao fundo e alíquotas de participação. Os resultados podem ser visualizados na Tabela 5.

Tabela 5 - Análise descritiva do percentual de conhecimento da Lei no 12.618 , adesão ao fundo e alíquotas segundo os que aderiram e não aderiram

\begin{tabular}{|c|c|c|c|}
\hline Variável & Valores & $\begin{array}{c}\text { Aderiu FUNPRESP } \\
(\%)\end{array}$ & $\begin{array}{c}\text { Não aderiu } \\
\text { FUNPRESP }(\%)\end{array}$ \\
\hline \multirow{3}{*}{$\begin{array}{l}\text { A partir de fevereiro de } 2013 \\
\text { os Servidores Públicos } \\
\text { Federais têm a opção } \\
\text { de aderir ao Fundo de } \\
\text { Previdência Complementar } \\
\text { denominado FUNPRESP. } \\
\text { Você sabia desta informação? }\end{array}$} & Não. Nunca ouvi falar. & 7,14 & 4,55 \\
\hline & $\begin{array}{c}\text { Sim. Sabia } \\
\text { superficialmente. }\end{array}$ & 57,14 & 77,27 \\
\hline & $\begin{array}{l}\text { Sim. Li e Conheço as } \\
\text { regras. }\end{array}$ & 35,71 & 18,18 \\
\hline \multirow{3}{*}{$\begin{array}{l}\text { Segundo a lei } 12.618 \text {, de } \\
30 \text { de abril de } 2012 \text {, sua } \\
\text { aposentadoria será dada } \\
\text { pelo teto do INSS onde o } \\
\text { valor atual (06/2015) é de R\$ } \\
4.663,15 \text {. Você sabia desta } \\
\text { informação? }\end{array}$} & Não, nunca ouvi falar. & 0,00 & 0,00 \\
\hline & $\begin{array}{c}\text { Sim. Conheço } \\
\text { superficialmente. }\end{array}$ & 64,29 & 68,18 \\
\hline & $\begin{array}{l}\text { Sim. Li e Conheço as } \\
\text { regras. }\end{array}$ & 35,71 & 31,82 \\
\hline \multirow{3}{*}{$\begin{array}{l}\text { O FUNPRESP é um } \\
\text { Fundo de Previdência } \\
\text { Complementar criado pelo } \\
\text { Governo Federal onde } 0 \\
\text { servidor público complementa } \\
\text { sua aposentadoria através } \\
\text { de poupanças individuais } \\
\text { com alíquota de } 8,5 \% \text {, } \\
8 \% \text { ou } 7,5 \% \text {. Você tinha } \\
\text { conhecimento desta } \\
\text { informação? }\end{array}$} & Não, nunca ouvi falar. & 7,14 & 13,64 \\
\hline & $\begin{array}{c}\text { Sim. Tinha } \\
\text { superficialmente. }\end{array}$ & 57,14 & 77,27 \\
\hline & $\begin{array}{l}\text { Sim. Li e Conheço as } \\
\text { regras. }\end{array}$ & 35,71 & 9,09 \\
\hline
\end{tabular}

Fonte: Elaborada pelos autores. 
Quando questionados sobre o conhecimento da opção de aderir ao FUNPRESP a partir de fevereiro de $2013,57,14 \%$ dos que aderiram sabiam da opção com superficialidade e $35,71 \%$ leram e realmente conheciam as regras. Dentre os que não aderiram, $77,27 \%$ sabiam superficialmente, contudo, apenas $18,18 \%$ leram e têm conhecimento das regras. Verifica-se, assim, que os servidores que aderiram à FUNPRESP possuem um conhecimento mais aprofundado das regras, pois as leram e as conhecem, diferentemente dos que não aderiram, onde mais de $75 \%$ conhecem apenas superficialmente.

Em se tratando do conhecimento da Lei $\mathrm{n}^{\circ} 12.618 / 12$, a qual embasa o valor da aposentadoria pelo teto no INSS, os servidores que aderiram, em sua maioria $(64,29 \%)$ conheciam superficialmente, o que aconteceu também com os que não aderiram $(68,18 \%)$. Percebe-se, porém, que dos que aderiram a percentagem é maior para os que leram e conhecem as regras $(35,71 \%)$ se comparado aos que não aderiram $(31,82 \%)$. Por fim, lhes foi questionado do conhecimento sobre o fato da FUNPRESP ter sido criada pelo Governo Federal para a complementação da aposentadoria, sendo que o servidor pode optar por diferentes alíquotas $(8,5 \%, 8 \%$ e $7,5 \%)$. Dos que aderiram $57,14 \%$ sabiam superficialmente, porém $35,71 \%$ leram e conhecem as regras. Dos que não aderiram, a percentagem de conhecimento superficial foi maior $(77,27 \%)$.

Verifica-se, dessa forma, que tanto os entrevistados que aderiram quanto os que não aderiram conhecem a lei do fundo de previdência complementar com superficialidade, porém os que aderiram possuem maior conhecimento das regras e buscaram, antes da adesão, informações mais detalhadas da FUNPRESP e das alíquotas da aposentadoria. Infere-se assim, que a não adesão se dá muitas vezes em função dos indivíduos não se preocuparem com a aposentadoria e não buscarem as regras e maior leitura sobre leis relacionadas à aposentadoria e à FUNPRESP. Após a análise de conhecimento inicial, são apresentados os percentuais de resposta de cada questão e a média de todas as questões referentes ao conhecimento geral dos que aderiram e não aderiram (Tabela 6). 


\section{OS SERVIDORES PÚBLICOS ESTÃO ADERINDO A FUNPRESP? UM ESTUDO EM UMA INSTITUIÇÃO FEDERAL DE ENSINO}

Tabela 6 - Descrição do nível de conhecimento sobre a

FUNPRESP segundo os que aderiram e não aderiram

\begin{tabular}{|c|c|c|c|c|c|c|c|c|c|c|}
\hline \multirow[b]{2}{*}{ Variáveis } & \multicolumn{2}{|c|}{ Média } & \multicolumn{2}{|c|}{ Não sei } & \multicolumn{2}{|c|}{ Discordo } & \multicolumn{2}{|c|}{ Indiferente } & \multicolumn{2}{|c|}{ Concordo } \\
\hline & Aderiu & $\begin{array}{l}\text { Não } \\
\text { aderiu }\end{array}$ & Aderiu & $\begin{array}{c}\text { Não } \\
\text { aderiu }\end{array}$ & Aderiu & $\begin{array}{l}\text { Não } \\
\text { Aderiu }\end{array}$ & Aderiu & $\begin{array}{l}\text { Não } \\
\text { Aderiu }\end{array}$ & Aderiu & $\begin{array}{l}\text { Não } \\
\text { Aderil }\end{array}$ \\
\hline $\begin{array}{l}\text { Conheço o Fundo } \\
\text { de Previdência } \\
\text { Complementar } \\
\text { do Servidor } \\
\text { Público Federal - } \\
\text { FUNPRESP. }\end{array}$ & 2,71 & 2,18 & 7,14 & 4,55 & 0,00 & 31,82 & 7,14 & 4,55 & 85,71 & 59,09 \\
\hline $\begin{array}{l}\text { Conheço o plano de } \\
\text { benefícios do Plano } \\
\text { de Previdência } \\
\text { Complementar. }\end{array}$ & 2,14 & 2,18 & 7,14 & 0,00 & 28,57 & 27,27 & 7,14 & 27,27 & 57,14 & 45,45 \\
\hline $\begin{array}{l}\text { Acompanho os } \\
\text { relatórios mensais } \\
\text { enviados pela } \\
\text { FUNPRESP. }\end{array}$ & 1,14 & 1,09 & 35,71 & 22,73 & 35,71 & 50,00 & 7,14 & 22,73 & 21,43 & 4,55 \\
\hline $\begin{array}{l}\text { Conheço o } \\
\text { regulamento } \\
\text { do Plano de } \\
\text { Previdência } \\
\text { Complementar. }\end{array}$ & 1,79 & 1,86 & 14,29 & 9,09 & 35,71 & 40,91 & 7,14 & 4,55 & 42,86 & 45,45 \\
\hline $\begin{array}{l}\text { Conheço as formas } \\
\text { de pagamento } \\
\text { do Plano de } \\
\text { Previdência } \\
\text { Complementar. }\end{array}$ & 2,00 & 1,82 & 14,29 & 13,64 & 28,57 & 31,82 & 0,00 & 13,64 & 57,14 & 40,91 \\
\hline $\begin{array}{l}\text { Sei o quanto é } \\
\text { descontado do meu } \\
\text { salário para o Plano } \\
\text { de Previdência. }\end{array}$ & 2,64 & 2,36 & 0,00 & 4,55 & 14,29 & 18,18 & 7,14 & 13,64 & 78,57 & 63,64 \\
\hline $\begin{array}{l}\text { Sei quanto tempo } \\
\text { terei que contribuir } \\
\text { para o plano. }\end{array}$ & 1,64 & 1,86 & 21,43 & 18,18 & 28,57 & 22,73 & 14,29 & 13,64 & 35,71 & 45,45 \\
\hline $\begin{array}{l}\text { Conheço as } \\
\text { condições de } \\
\text { saída do Plano } \\
\text { de Previdência } \\
\text { Complementar. }\end{array}$ & 0,50 & 1,36 & 50,00 & 31,82 & 50,00 & 27,27 & 0,00 & 13,64 & 0,00 & 27,27 \\
\hline $\begin{array}{l}\text { Média do } \\
\text { Conhecimento Geral }\end{array}$ & 1,82 & 1,84 & & & & & & & & \\
\hline
\end{tabular}

Fonte: Elaborada pelos autores. 
Verifica-se que dentre os respondentes que aderiram a FUNPRESP, $85,71 \%$ declararam conhecer o fundo de previdência e $57,14 \%$ conhecem o plano de benefícios. Porém, $35,71 \%$ relatam não saber nada a respeito e $35,71 \%$ discordam acompanhar os relatórios mensais enviados pela fundação. Quanto ao conhecimento do regulamento do fundo, $42,90 \%$ concordam conhecer, contudo, um percentual bem elevado, 35,71\% relatam ainda não conhecer. Em relação à forma de pagamento, a mesma é conhecida por 57,14\% dos servidores, sendo que $78,60 \%$ sabem o quanto é descontado do salário para o pagamento do fundo. Quando questionados sobre quanto tempo ainda terá de contribuir para a aposentadoria, $35,71 \%$ dos respondentes concordaram saber o tempo, contudo, metade dos respondentes declarou não saber o tempo restante. Tratando-se do conhecimento acerca das condições de saída do plano, $100 \%$ dos servidores relataram não saber ou desconhecer essas condições, o que se torna um dado bastante alarmante.

Quanto aos entrevistados que não aderiram à FUNPRESP, $59,09 \%$ conheciam o fundo de previdência complementar do servidor público federal, contudo, menos da metade $(45,45 \%)$ relatou conhecer o plano de benefícios. Quanto ao fato de acompanharem os relatórios mensais, 50\% não acompanham e $22,70 \%$ não sabem a respeito. Quando perguntados se conhecem o regulamento do plano, $50,00 \%$ não sabem acerca do assunto ou discordam conhecer o regulamento, porém $45,50 \%$ concordam conhecer, mas não realizaram a adesão. Referente às formas de pagamento do plano, $40,90 \%$ disseram que conhecem e $45,40 \%$ discordam conhecer ou não sabem a respeito. Quando questionados sobre o conhecimento do quanto é descontado do salário para contribuição ao plano, a maioria $(63,60 \%)$ diz conhecer o valor do desconto. Quanto ao tempo de contribuição, $45,50 \%$ declaram ser cientes de quanto tempo teriam que contribuir para o plano, contudo, $40,90 \%$ discordam saber o tempo de contribuição ou não sabem a respeito. Por fim, a maioria dos entrevistados não sabe a respeito ou discorda conhecer as condições de saída do plano $(59,10 \%)$ caso aderissem. Tanto entre os servidores que aderiram, quanto os que não aderiram, constatou-se um alto percentual na opção não sei nas questões referentes a acompanhar os relatórios e condições de saída do plano. Além disso, um maior percentual de servidores que não aderiram relatam discordar conhecer as formas de pagamento, quanto é descontado do salário e um menor percentual sabe quanto tempo terá que contribuir e as condições de saída. 


\section{OS SERVIDORES PÚBLICOS ESTÃO ADERINDO A FUNPRESP? UM ESTUDO EM UMA INSTITUICÃO FEDERAL DE ENSINO}

Esses resultados indicam um menor conhecimento dos indivíduos sem adesão e, se essas pessoas tivessem maiores informações do regulamento e da FUNPRESP em geral, talvez pudessem aderir ao fundo.

Tanto os servidores que aderiram, quanto os que não aderiram à FUNPRESP possuem o mesmo nível de conhecimento. Em relação aos que aderiram, esses obtiveram melhores médias nas questões relativas a conhecer a FUNPRESP, acompanhar os relatórios mensais, conhecer as formas de pagamento do plano e saber o quanto é descontado do salário. Quanto aos que não aderiram, as melhores médias foram nas questões relacionadas a conhecer o plano de benefícios, conhecer o regulamento do plano, o tempo de contribuição e as condições de saída. Após a análise de conhecimento buscou-se verificar as variáveis de risco e retorno financeiro, descritas na Tabela 7 .

Tabela 7 - Descrição da percepção de riscos e retornos financeiros advindos da FUNPRESP segundo os que aderiram e não aderiram

\begin{tabular}{|c|c|c|c|c|c|c|c|c|c|c|}
\hline \multirow{2}{*}{ Variáveis } & \multicolumn{2}{|c|}{ Média } & \multicolumn{2}{|c|}{ Não sei } & \multicolumn{2}{|c|}{ Discordo } & \multicolumn{2}{|c|}{ Indiferente } & \multicolumn{2}{|c|}{ Concordo } \\
\hline & Aderiu & $\begin{array}{c}\text { Não } \\
\text { aderiu }\end{array}$ & Aderiu & $\begin{array}{c}\text { Não } \\
\text { aderiu }\end{array}$ & Aderiu & $\begin{array}{c}\text { Não } \\
\text { aderiu }\end{array}$ & Aderiu & $\begin{array}{l}\text { Não } \\
\text { aderiu }\end{array}$ & Aderiu & $\begin{array}{l}\text { Não } \\
\text { aderiu }\end{array}$ \\
\hline $\begin{array}{l}\text { Existe um } \\
\text { alto risco de a } \\
\text { FUNPRESP não } \\
\text { conseguir pagar } \\
\text { os benefícios } \\
\text { contratados. }\end{array}$ & 0,93 & 1,18 & 57,14 & 45,45 & 14,29 & 18,18 & 7,14 & 9,09 & 21,43 & 27,27 \\
\hline $\begin{array}{l}\text { Espero que } \\
\text { o Fundo de } \\
\text { Previdência seja } \\
\text { suficiente para } \\
\text { que a minha renda } \\
\text { se mantenha a } \\
\text { mesma após a } \\
\text { aposentadoria. }\end{array}$ & 1,93 & 1,68 & 28,57 & 40,91 & 7,14 & 0,00 & 7,14 & 9,09 & 57,14 & 50,00 \\
\hline
\end{tabular}




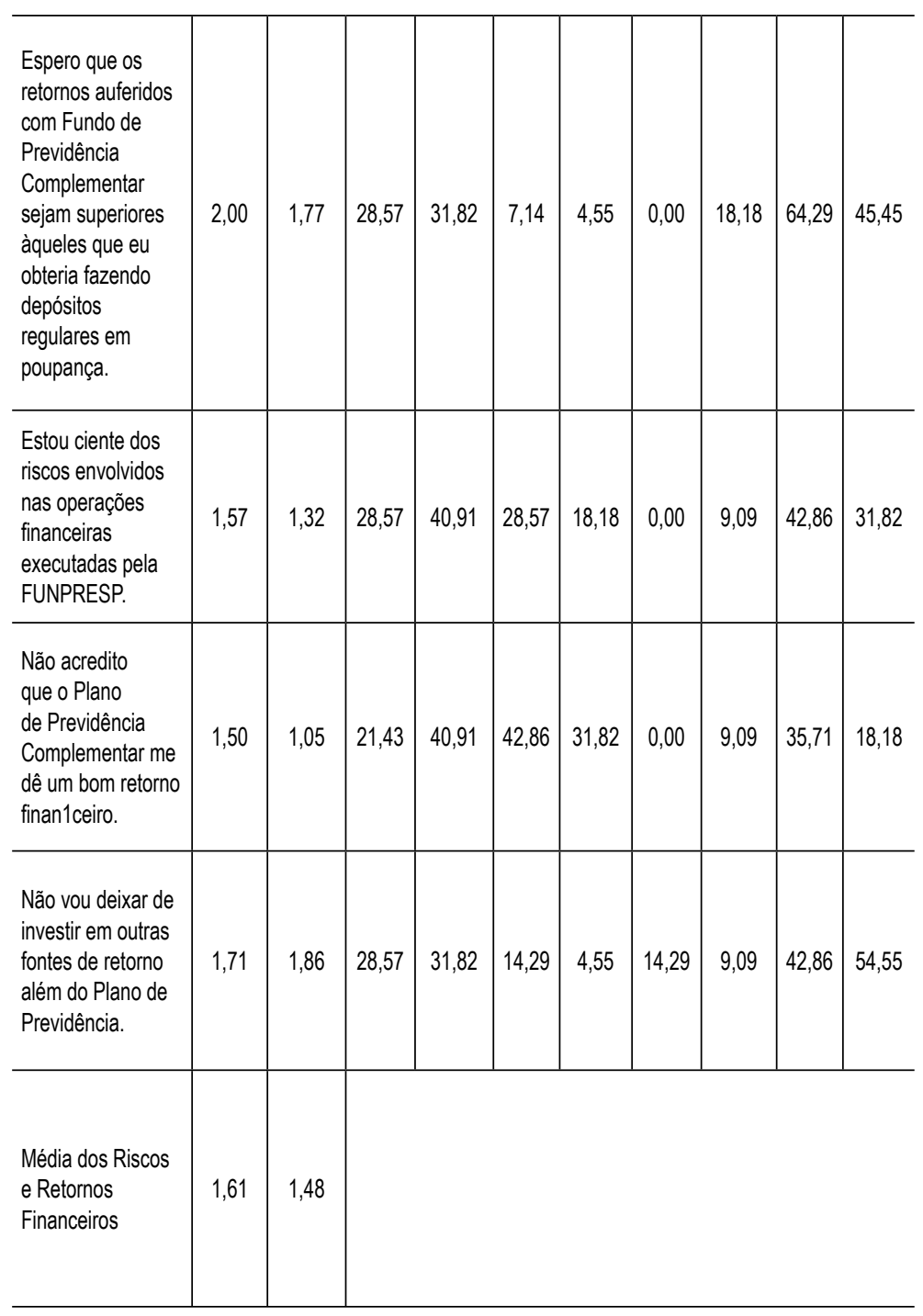

Fonte: Elaborada pelos autores.

Ao analisar-se o conhecimento dos servidores quanto aos riscos e retornos inerentes ao fundo de previdência complementar, observou-se que dentre os que aderiram à FUNPRESP a maioria 


\section{OS SERVIDORES PÚBLICOS ESTÃO ADERINDO A FUNPRESP? UM ESTUDO EM UMA INSTITUIÇÃO FEDERAL DE ENSINO}

$(57,14 \%)$ não sabe se existe alto risco da FUNPRESP não conseguir pagar os benefícios contratados e apenas $14,29 \%$ discordam de haver altos riscos. Verificou-se, ainda, que $57,14 \%$ dos servidores esperam que o fundo de previdência seja suficiente para que a renda se mantenha a mesma após a aposentadoria. Contudo, um percentual de cerca de $30 \%$ declarou não saber sobre essa questão. Percebeu-se que a maioria dos respondentes $(64,29 \%)$ espera ter melhores resultados com o fundo do que se tivessem investido em poupança. Mais da metade dos servidores $(57,14 \%)$ declarou não saber ou discordam estar cientes dos riscos envolvidos nas operações financeiras do fundo, e a maior parte $(42,86 \%)$ acredita que o fundo irá lhe proporcionar um bom retorno financeiro e não vai deixar de investir em outras fontes de investimento $(42,86 \%)$.

Em relação aos servidores que não aderiram, $45,45 \%$ não sabem se existe um alto risco da FUNPRESP não conseguir pagar os benefícios contratados e $27,27 \%$ relatam concordar que existe um alto risco. A metade dos servidores concorda que o fundo de previdência seria suficiente para que a renda se mantivesse a mesma depois da aposentadoria e $40,91 \%$ declaram não saber a respeito. A maior parte dos respondentes $(45,45 \%)$ relata acreditar que os retornos do fundo sejam superiores a poupança e um alto percentual $(31,82 \%)$ não sabe a respeito. Quanto a estar ciente dos riscos envolvidos, $18,18 \%$ afirmam não saber dos riscos e $31,82 \%$ relata estar ciente. A maior parte dos servidores (40,91\%) afirmou não saber sobre os retornos financeiros da previdência complementar e 31,82 $\%$ acreditam em um bom retorno financeiro. A maioria dos respondentes $(54,55 \%)$ relata que não deixaria de investir em outras fontes além do plano de previdência.

Considerando que são pessoas jovens (média de 30 anos), estes fatores impactam diretamente na aposentadoria dos servidores, pois se percebe que os mesmos têm a pretensão de se aposentar com um salário estável, porém a atitude é contrária. Este pode ser um dos pontos de a maioria não ter aderido e de haver dúvidas quanto ao mesmo, pois ainda há resistência quanto à adesão por falta de conhecimento. Por fim, foi investigado o nível de informações acerca da FUNPRESP, daqueles que aderiram ao fundo (Tabela 8). 
Tatiane Sartori $\mid$ Luana dos S. Fraga $\mid$ Kelmara M. Vieira $\mid$ Daniel A. Coronel

Tabela 8 - Descrição do nível de informação sobre a FUNPRESP segundo os que aderiram

\begin{tabular}{l|c|c|c|c|c}
\hline \multicolumn{1}{c|}{ Variáveis } & Média & Não Sei & Discordo & Indiferente & Concordo \\
\hline $\begin{array}{l}\text { A FUNPRESP fornece um nível } \\
\text { adequado de informações sobre os } \\
\text { contratos. }\end{array}$ & 1,14 & 21,43 & 50,00 & 21,43 & 7,14 \\
\hline $\begin{array}{l}\text { A FUNPRESP fornece relatórios } \\
\text { atualizados sobre a situação da minha } \\
\text { previdência. }\end{array}$ & 1,21 & 35,71 & 21,43 & 28,57 & 14,29 \\
\hline $\begin{array}{l}\text { A FUNPRESP me informa com } \\
\text { antecedência sobre os ajustes e } \\
\text { reajustes das minhas parcelas. }\end{array}$ & 0,57 & 57,14 & 35,71 & 0,00 & 7,14 \\
\hline Média de informações & 0,97 & & & & \\
\hline
\end{tabular}

Fonte: Elaborada pelos autores.

Dentre os servidores que aderiram, $50 \%$ discordam que as informações fornecidas pela FUNPRESP são adequadas e apenas $7,14 \%$ concordam. Em se tratando dos relatórios atualizados, $35,71 \%$ não sabem do fornecimento de relatórios e $21,43 \%$ discordam que a FUNPRESP fornece relatórios sobre a situação de sua previdência. A maioria dos servidores $(92,85 \%)$ relata não saber a respeito ou discordar sobre o fato de que a FUNPRESP informa com antecedência os ajustes e reajustes das parcelas. Observa-se que o nível de informações é baixo, pois a média ficou em torno de 1, ou seja, os respondentes discordam quanto a receber informações relevantes da FUNPRESP. A pior média foi em relação aos indivíduos serem informados com antecedência sobre o os ajustes da parcela, $o$ que demonstra a carência de informações por parte dos que aderiram ao fundo.

\section{CONCLUSÃO}

Diante da mudança da regra de aposentadoria, a partir de fevereiro de 2013, em que o valor do benefício previdenciário máximo é o valor do teto do INSS, a aposentadoria e a adesão a planos de previdência complementar se tornam assuntos muito relevantes no contexto dos servidores públicos federais. Dessa forma, o presente estudo teve como objetivos identificar o percentual de adesões dos servidores de um dos Campi de uma Universidade Federal ao Plano de Previdência Complementar FUNPRESP, além de descrever o perfil desses, avaliar os motivos da adesão e não adesão e verificar 


\section{OS SERVIDORES PÚBLICOS ESTÃO ADERINDO A FUNPRESP? UM ESTUDO EM UMA INSTITUIÇÃO FEDERAL DE ENSINO}

o nível de conhecimento e informações sobre a FUNPRESP. Inicialmente verificou-se que, mesmo tendo recebido informações por parte de um representante da FUNPRESP, a maioria dos servidores não aderiu ao plano e isso pode ser justificado pela ausência de conhecimento sobre o fundo. A grande maioria diz que conhece o plano superficialmente, contudo não lê as regras mais detalhadamente e isso pode se tornar uma das razões de não haver maior adesão por parte dos novos servidores. Percebeu-se, ainda, que a renda pode ser um dos motivos da adesão, já que a maior parte dos que aderiram são professores universitários, com faixa salarial maior.

Observou-se também que a maioria dos que aderiram ao plano buscaram informações voltadas aos benefícios e tipos de resgates e aderiram por achar a FUNPRESP mais vantajosa do que um plano de previdência privado, sendo também a única opção apresentada quando da sua entrada na Universidade. Para a maioria que não aderiu, o motivo está vinculado a acreditar que outros investimentos serão mais rentáveis para sua aposentadoria. Do ponto de vista do conhecimento quanto ao fundo, o presente estudo identificou que ainda há necessidade de esclarecimento por parte da Universidade e dos representantes da FUNPRESP, sendo que a maioria dos servidores pretende aderir ao fundo de previdência complementar no futuro, mas não buscaram maiores informações para aderir no presente momento. Em relação às informações disponibilizadas pela FUNPRESP aos servidores que aderiram ao plano, constatou-se que a maioria dos respondentes discordam quanto a receber informações importantes, como os ajustes da parcela e relatórios atualizados da sua situação. Assim, esse fato torna-se relevante no sentido que pode levar a desistências do plano e a não adesão por outros servidores que poderiam se interessar.

Diante do que foi apresentado no estudo, o servidor público federal tem pensado em sua aposentadoria, porém não se sentiu seguro e desconhece as vantagens em aderir ao FUNPRESP. Dessa forma, ações de melhoria se tornam necessárias quanto à forma de apresentar o plano, as propostas e limitações do FUNPRESP, para que o número de adesões aumente e para que o servidor se sinta mais seguro para aderir. $\mathrm{O}$ servidor está preocupado com a sua aposentadoria, porém faltam ações efetivas dos mesmos, quanto à busca de melhores rendimentos que irão garantir uma aposentadoria estável. 
O cenário atual de reformas na previdência aponta para incertezas com previsão de aumento do tempo para a aposentadoria. $\mathrm{O}$ déficit previdenciário sugere que os cidadãos precisam buscar alternativas para manter sua renda após se aposentarem. A presente pesquisa aponta a necessidade do servidor público buscar maiores informações sobre a previdência complementar, pois estando estes no novo regime de previdência, o qual trabalha com o teto do INSS, precisa se precaver para o futuro. Atualmente o servidor possui renda, mas não está preocupado com seu futuro financeiro frente a aposentadoria, e se não buscar formas de investimento e informações acerca de previdência complementar, este servidor claramente não terá rendimentos de mesmo nível que o atual, ao se aposentar.

Como limitações, tem-se a falta de estudos já realizados sobre o assunto e a inexistência de escalas já validadas que investiguem a mesma temática da presente pesquisa. Sugere-se para estudos futuros a ampliação da amostra, para que assim possam ser comparados os resultados.

\section{REFERÊNCIAS}

AMARAL, F. V. A.; GIAMBIAGI, F.; CAETANO, M. O Fundo Previdenciário dos Servidores da União: Resultados Atuariais. Pesquisa e Planejamento Econômico, Rio de Janeiro, v. 43, n. 1, p. 119-160, abr. 2013.

BARRO, R. The impact of social security on private saving. Washington, DC: American Enterprise Institute, 1978.

BOWERS, N. L. Actuarial mathematics. 2. ed. Schaumburg, Ill.: Society of Actuaries, 1997.

BRASIL. Presidência da República. Lei 12.618 de 30 de abril de 2012. Institui o regime de previdência complementar para os servidores públicos federais titulares de cargo efetivo. Diário Oficial da União, Brasília, DF, 2012.

. Ministério da Educação. Plano de Carreira dos Técnicos Administrativos da Educação. Brasília, DF, [2016]. Disponível em:< www.portal.mec.com.br>. Acesso em: 1 out. 2016.

. Portaria n. 154, de 15 de maio de 2008. Disciplina procedimentos sobre a emissão de certidão de tempo de contribuição pelos regimes próprios de previdência social. Diário Oficial da União, Brasília, DF, 2008. 


\section{OS SERVIDORES PÚBLICOS ESTÃO ADERINDO A FUNPRESP? UM ESTUDO EM UMA INSTITUICYAOO FEDERAL DE ENSINO}

CAMPOS, M. B. B. Regime próprio de previdência social dos servidores públicos. 3. ed. Curitiba: Juruá, 2011.

CARDOSO, S. et al. Pequenas e médias empresas como patrocinadoras de planos previdenciais em entidades fechadas de previdência complementar. Revista Contabilidade e Finanças, São Paulo, v. 17, n. 2, dez. 2006.

CHAGAS, C. et al. Paulo, ser ou não ser um servidor público?: o caso dos novos servidores públicos que irão se aposentar pelo teto do INSS. Brasília, DF: Casoteca de Gestão Pública, 2015.

COIMBRA, L. W. P.; TOYOSHIMA, S. H. Uma análise do setor de previdência complementar brasileiro. Revista Economia Contemporânea, Rio de Janeiro, v. 13, n. 3, p. 439-466, dez, 2009.

DAVIS, E. P. Regulation of privale pensions: a case Study of the UK. Inglaterra: The Pensions Institute, Birkbeck CoHege; Universidade de Londres, 2000.

FERREIRA, G. G. Condições atuariais para a construção do fundo previdenciário federal - FUNPRESP. 2008. 85 f. Dissertação (Mestrado em Economia) - Faculdade de Economia, Administração e Contabilidade, Universidade de São Paulo, São Paulo, 2008.

FUNDAÇÃO DA PREVIDÊNCIA COMPLEMENTAR O SERVIDOR PÚBLICO FEDERAL. Relatório Anual de Informações 2014. Brasília, DF, 2015. Disponível em:<https://www.funpresp.com. br/portal/?page_id=3749>. Acesso em: 2 maio 2016.

Relatório Anual de Informações 2015. Brasília, DF, 2016. Disponível em:<https://www.funpresp.com.br/portal/?page_id=3749>. Acesso em: 2 maio 2016.

GOES, H. Manual do direito previdenciário. 4. ed. Rio de Janeiro: Editora Ferreira, 2011.

INSTITUTO NACIONAL DO SEGURO SOCIAL. Tabela de contribuição mensal. Brasília, DF, 2016. Disponível em:<www. previdencia.com.br>. Acesso em: 1 out. 2016.

MARINHO, A. R.; AFONSO, L. E. Análise Atuarial da Fundação de Previdência Complementar dos Servidores Públicos Federais (FUNPRESP). In: CONGRESSO DE CONTROLADORIA E CONTABILIDADE DA USP, 14., São Paulo. Anais... São Paulo: USP, 2014. Disponível em:<www.congressousp.fipecafi.org/web/ artigos 142014/an_resumo.asp?pagina $=36 \ldots 1>$. Acesso em: 2 maio 2016. 
MONTESINOS, D. S. Previdência Complementar: estudo de caso Plano Fechado de Previdência Complementar. 2007. 83 f. Trabalho de Conclusão de Curso (Graduação em Ciências Contábeis) Universidade Federal de Santa Catarina, Florianópolis, 2007.

PACHECO FILHO, C; WINCKLER, C. R. Reforma na Previdência: o ajuste no setor público. Indicadores Econômicos, Porto Alegre, v. 32, n. 4, p. 221-248, mar. 2005.

PENA, R. FUNPRESP: alicerce para o futuro da previdência complementar. Coletânea ABRAPP, São Paulo, 2014.

. Previdência Complementar no Brasil: História, evolução e desafios. Revista Fundos de Pensão, São Paulo, ano XXVII, n. 340, p. 13-15, 2012.

PINHEIRO, R. P. Educação financeira e previdenciária, a nova fronteira dos fundos de pensão. In: REIS, A. (Orgs.). Fundos de Pensão e mercado de Capitais. São Paulo: Instituto San Tiago Dantas de Direito e Economia: Editora Peixoto Neto, 2008.

REZENDE, F. Finanças Públicas. 2. ed. São Paulo: Atlas, 2001.

SANTOS, D. F. C. A previdência social no Brasil: 1923-2009 - uma visão econômica. Porto Alegre, RS: AGE, 2009.

SILVEIRA, F. G. et al. Previdência dos servidores públicos: reflexões em torno da proposta de instituição da previdência complementar. Texto para Discussão, Rio de Janeiro, n. 1679, dez. 2011.

VAZ, L. R. O princípio do equilíbrio financeiro e atuarial no sistema previdenciário brasileiro. Revista Direitos Fundamentais e Democracia, Curitiba, v. 6, 2009.

WINKLEVOSS, H. E. Pension mathematics with numerical illustrations. 2. ed. Philadelphia: Wharton School of the University of Pennsylvania, published by Pension Research Council, 1993. 